\title{
Trust and Forgiveness in Virtual Teams: A Study in Algerian E-Learning Context
}

\author{
Meriem Laifa \\ Department of Computer \\ science \\ BBA University, Algeria \\ meriem.laifa@gmail.com
}

\author{
Roya Imani Giglou \\ Institute for media studies \\ Catholic University of Leuven, \\ Belgium \\ roya.imanigiglou@soc.kuleuven.be
}

\author{
Samir Akhrouf \\ Department of Computer \\ science \\ BBA University, Algeria \\ Samir.akrouf@gmail.com
}

\author{
Ramdane Maamri \\ Computer science \\ Constantine 2 University, \\ Algeria \\ mameri@yahoo.fr
}

\begin{abstract}
E- learning is gaining more popularity due to the technological development and the personalization it offers for learners and organizations. Most e-learning platforms support group work and collaboration between learners, which is a desirable educational practice. Thus, virtual team members must be flexible to achieve their goals in a cooperative environment. In order to improve learners experiences, and to encourage collaboration between them, we propose and validate a theoretical model that predicts the effect of trust on learners' forgiveness when a conflict occurs in a virtual team.
\end{abstract}

Keywords-Forgiveness; trust; e-learning; virtual teams.

\section{INTRODUCTION}

Digital technology has continued to evolve rapidly during the last decades, smashing the traditional learning model by supporting online exchanges of visuals, text, and audio within the learning community. The benefits gained from the use of networked information and communications technology in teaching and learning created a recent new buzzword; that is elearning. E-learning is defined as "instruction delivered on a digital device such as a computer or mobile device that is designed to support individual learning or organizational performance goals" [2]. E-learning courses include both content and techniques that help people learn using illustrations, animation, or videos [2]. Moreover, computers and mobile devices offer a simulated environment that is very hard to replicate in real world. This feature offers strong promises for human learning processes by giving the learners the opportunity to resolve hard problems in a realistic environment $[2,10]$. On the other hand, e-learning provides customized and adaptive learning which can save time and high costs [10]. It also encourages learners' engagement by setting up a combination of texts, audio and visual contents [10].

In a face-to-face learning environment, students' achievements are known to be improved by cooperative learning $[2,5]$. Thus, most e-learning platforms support virtual group work and collaboration between learners, which is a desirable educational practice. Nevertheless, learners may fall in conflict with their peers when they work together on the same project. Consequently, team members must be flexible to achieve their goals in a cooperative environment. Social interdependence and high level of trust are two important success criteria for successful collaborations [2,9]. On the other hand, trust plays an important role in enhancing collaboration and cooperation for computer-mediated communication (CMC) [8]. Furthermore, forgiveness is claimed to repair broken relationships in offline interactions [3]. In order to improve learners experiences, and to encourage collaboration between them, we propose in this paper, a theoretical model that predicts the effect of trust on learners' forgiveness when a conflict occurs in a virtual team. Our study concerns an Algerian elearning platform of the university of Bordj Bou Arreridj ${ }^{1}$.

The following sections are divided as follows: in section 2, we provide a theoretical background of our research questions of this study. In section 3, we explain the used methods and data collection. Section 4 explains the primary results of the analysis. Finally, results and further research opportunities are discussed in section 5 .

\section{THEORY}

\section{A. Trust}

There is an abundance of research on defining and computing trust, and describing its important factors by leaning basically on psychology and sociology. Trust is defined as "the belief that the trustee (the virtual team's members in our study) will act in the best interests of the trustor ( the learner) in a given situation, even when controls are unavailable and it may not be in the trustee's best interests to do so" [13].

Trust is required to back up successful interactions and to maintain the cooperation between individuals $[1,4,9]$. In addition, trust improves organizational and group performance [15]. On the other hand, trust relationships within teams increase cooperation by reducing uncertainty, and conduct to better results [16]. However, it is difficult to build trust in a virtual context. Gedeon [15] proposed a framework for trust management as a tool for building, managing and repairing trust between employees. His framework includes three main constructs that affect individuals trusting intentions [15]: (1) propensity to trust (i.e. individuals' general attitudes toward trust), (2) institutional trust (i.e. social factors that might impact on whether or not the other person lives up to his or her side of the relationship) and (3) perceived trustworthiness (i.e. the

${ }^{1}$ http://elearning.univ-bba.dz/ 
trustor's perception of the trustee's). In this paper, we focus on the first construct, which is propensity to trust.

There is a wealth of research on computer-mediated communication and research on culture influence. However, cross-cultural computer-mediated communication research is not studied in depth. As part of the first research question, we will consider the possible influence of Algerian culture on trusting intentions toward the virtual team in e-learning. Consequently, our first research question that we like to answer is the following:

Q1. What are Algerians' trust intentions toward their virtual teams in e-learning context?

\section{B. Forgiveness}

Forgiveness is a set of prosocial motivational changes that occurs after an offense, and it involves decreasing negative affect and/or behaviors and increasing positive ones, towards an offender who does not necessarily deserve these changes [6]. Studies from different disciplines have shown the importance and benefits of forgiveness on the forgiver and the forgiven. It reduces negative emotions and sustains healthy relationships [11]. Forgiveness has also positive effects on health and wellbeing [11]. On the other hand, forgiveness may improve connectedness and cooperation within the community by increasing empathy and understanding between community members, as well as reducing guilt and reinforcing solutions for conflicts $[3,4,11]$. Therefore, we aim to investigate forgiveness in e-learning, more precisely in virtual teams, in an attempt to improve learners' experience and decrease conflicts rates between the team's members.

Forgiveness is a complicated concept, and depends, directly and indirectly, on many factors which are: empathy, personality, commitment, apology, severity and frequency of the offense [6,11]. Moreover, pre-transgression trust is an important consideration in understanding individuals' tendency to forgive their offenders and restore the relationships [3]. Therefore, we aim in this study to answer two main questions about learners trust effects on their forgiveness decision towards their virtual teams. Consequently, the second and third research questions we aim to answer are the following (see figure for the proposed theoretical model):

Q2. Does the victim propensity to trust affect his/her forgiveness?

Q3. Do trusting intentions towards virtual teams affect a victim forgiveness?

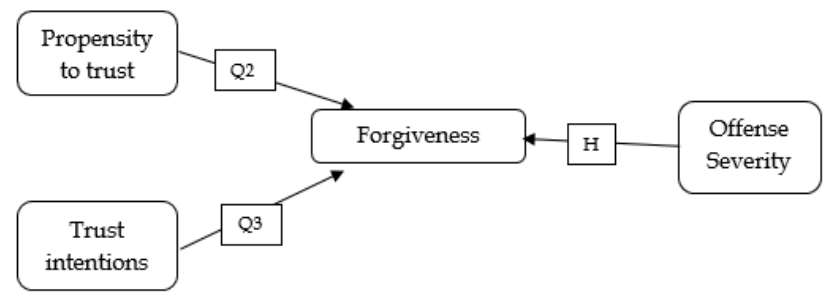

Fig. 1. Theoretical Model
In the offline world, many experiments in psychology confirmed that severe offenses are more difficult to be forgiven. Fincham et al [12] experiments on examining subjective and objective offense's severity revealed that both perspectives predicted forgiveness and affected it negatively. In addition, a meta-analysis on forgiveness antecedents and consequences proved that the severity of the offense negatively affects interpersonal forgiveness [11]. Accordingly, we assume that the severity of the offense of the virtual team members can affect the victim forgiveness, and we presume the following hypothesis:

H. The severity of the offense relates negatively to the victim forgiveness decision.

\section{METHODS}

In this section, we present different scales we used to measure each of the model constructs. We also explain our data collection procedure

\section{A. Scales}

Based upon the research questions, a self-administered survey was designed as the appropriate technique of measurement. The used items to measure the model constructs came from a number of sources. In this section, we explain each of these items. All trust scales items are positively worded to avoid any confusion with other negative concepts like distrust.

Propensity to trust: also called disposition to trust, is defined as a general tendency to trust others, which can influence an individual's beliefs and intentions towards a virtual team and its members, therefore, it is important to include it in our model $[1,7]$. In this study, we adopted Mayer and Davis propensity to trust scale [7]. It is an eight-item scale, and it is validated by many other researchers [15]. The scale is shown in the Appendix.

Trusting intentions: in the theory of planned behavior [16], intentions have been found to be the greatest predictor of planned behavior. Therefore, asking participants about their trusting intent allow us to both predict and reinforce their future behavior towards their offenders. Trusting intention is the truster willingness to securely depend on the trustee [1]. For this, we adopted a short version of McKnight et al [1] trusting intention scale. This scale is divided into two constructs: 3items to measure the learners' willingness to depend on their virtual team ("volitional preparedness to make oneself vulnerable to the trustee"), and the subjective probability of depending ("the perceived likelihood that one will depend on the other") [1]. Both items are shown in the Appendix.

Forgiveness: forgiveness involves decreasing negative affect and/or behaviors and increasing positive ones towards an offender. Based on McCullough et al [6] framework, there are two distinct motivations that together lead to unforgiving an offense. These motivations are avoiding contact with the offender, and seeking revenge. Reciprocally, when an offended partner forgives the offender, his or her motivation to avoid the offender or get revenge decrease. In our study, we used 
McCullough et al [6] forgiveness scale (also called Transgression-Related Interpersonal Motivations Inventory), which contains 12 items. Five items are used to measure revenge, while the other seven items are used to measure avoidance (see appendix).

\section{B. Participants and procedure}

Our study is concerned with Algerian learners. Thus, we shared the final version of the survey with our colleagues at the University of Bordj Bou Arreridj, and we asked them to share it with their colleagues as well. The survey has a French version too as it is a widely used language among Algerians. All items were endorsed on a 5-point Likert-type scale $(1=$ strongly agree, 5 = strongly disagree). We started the survey with an explanation of our intentions, confidentiality, and how long the survey can take. We also provided an email address for participants to send their questions and remarks.

We asked the participants to mention if they were familiar with e-learning platforms. Then, participants were asked to express to which degree they agree or disagree on each statement from propensity to trust scale. After that, we provided a scenario that can allow them to imagine the context of the study before answering the second part of the survey (i.e. trusting intention scale), as follows:

Please, keep in mind the following scenario when you evaluate the next statements.

"You enrolled in one of the provided online courses. Your instructor gives you an assignment that should be done in a virtual team. The virtual team is a group of four (04) participants who enrolled in the same course, and they can be from any other Algerian university."

Next, we provided the second part of the scenario, where the virtual team committed an offense then we ask participants to express their opinion about each of the forgiveness scale items, as follows:

"Your virtual team delivers the assignment two days after its due date. This tardiness will likely affect the overall team's grade."

On the other hand, we wanted to know how severe this offense may seem to the participants, so we added a statement and asked them to rate how much they agree/disagree on it:

\section{"My virtual team tardiness is a very serious offense for me."}

In the end of the survey, we asked participants about their gender, age, level of completed education, marital status, and the language they used the most after Arabic (the official Algerian language). In one week, we collected 108 full responses (responses with missing values were excluded) where $65 \%$ of respondents were familiar with e-learning platforms. A general overview of the demographics of the respondents in this study is provided in table 1. Most respondents are young (under 30) and have a master degree.

\section{ANALYSIS}

Information were collected from respondents using an online survey. Data were analyzed with appropriate statistical tests by using SPSS and Amos software. In this study univariate statistics and bivariate statistics have been used to understand the composition, distribution, central tendency, deviation, and between-within group comparison of the sample, and to identify relevant correlations between the variables and find effective factors on our dependent variables before running the structural equation model (SEM). Finally, SEM has been selected to test the theoretical model and find out the best fitting model.

TABLE I. RESPENDENTS DEMOGRAPHICS

\begin{tabular}{lc}
\hline & Percentage \\
\hline Gender & \\
Male & $54.6 \%$ \\
Female & $45.4 \%$ \\
& \\
Age & \\
$<30$ & $86.1 \%$ \\
$\geq 30$ & $13.9 \%$ \\
Completed Educational Level & \\
Bachelor degree & $11.1 \%$ \\
Master degree & $74.1 \%$ \\
Doctorate & $6.5 \%$ \\
Post-doctorate program & $5.6 \%$ \\
No degree & $2.8 \%$ \\
Marital status & \\
Single & \\
Married or engaged & $63.9 \%$ \\
In a relationship & $26.9 \%$ \\
& $9.3 \%$ \\
Most used language after Arabic & \\
French & \\
English & $64.8 \%$ \\
Others & $29.6 \%$ \\
\hline
\end{tabular}

The reliability analysis of the survey constructs are shown in table 2 where the Cronbach's alpha values $(\alpha)$ were over the threshold of 0.600 . This means that the average intercorrelation among the variables was reliable enough to build the survey constructs as they measure the same construct.

The first goal of this study is to understand Algerian learners' trusting intentions toward their virtual teams to be able to improve their experiences and encourage collaboration between members. Based on the collected responses, most respondents tend to trust their virtual team $(59.3 \%)$, while only $8.3 \%$ of responses were negative.

When we conducted a linear regression analysis that attempted to predict the connections between different variables and forgiveness, we found that the significant predictors of forgiveness were subjective probability of depending and offense severity (Adj. R square $=0.31$; See Table 3 ). The results of this regression analysis support our hypothesis that the severity of the offense affects the victim decision to forgive. In addition, these results shows that the more learners intend to 
trust their virtual team, the more they tend to forgive their offenses.

We also employed Structural Equation Modeling analysis to evaluate the research model using AMOS SPSS. The theoretical model for testing interrelationshps between variables is dispalyed in figure 2. The standardized parameter estimation was loaded above pathways. Nevertheless, because of low sample size there was some weak goodness of indices. Goodness of Fit (GOF) and their acceptable thresholds for good fits are reported: $\mathrm{X}^{2}=382.79, \mathrm{df}=260(\mathrm{p}<0.001), \mathrm{X}^{2} / \mathrm{df}=1.47$ (must be lower than 3 ), $\mathrm{GFI}=0.79, \mathrm{CFI}=0.84$, IFI $=0.85$, $\mathrm{TLI}=0.82$ (must be upper than 0.90 ) and RMSEA $=0.066$ (must be lower than 0.08).

TABLE II. RELIABILITY OF SCALES

\begin{tabular}{lc}
\hline Scales (number of items) & $\begin{array}{c}\text { Cronbach's Alpha } \\
(\alpha)\end{array}$ \\
\hline Propensity to trust (8) & 0.600 \\
& \\
Trusting intentions (6) & 0.773 \\
Willingness to depend (3) & 0.717 \\
Subjective probability of depending (3) & 0.737 \\
Forgiveness (12) & 0.816 \\
\hline
\end{tabular}

Popensity to trust is a latent construcy with 6 observed indicators. Q2 2 has higher factor loading for this construct (lambda $=0.87, \mathrm{p}<0.001)$. Q2_1 and Q2_4 which are nonsignficant indicators were exculuded form the measurment model of this construct.

Trust to intension and forgiveness are latent with 6 and 12 indicators respictively. Q3_5 has higher factor loading for trust to intension construct (lambda $=0.81, \mathrm{p}<0.001)$ and Q4 5 for forgiveness has higher loading (lambda $=0.71, \mathrm{P}<0.001$ ). Q4_2 which was non-significant and exculuded from forgiveness construct.

TABLE III. PREDICTORS OF FORGIVENESS

\begin{tabular}{lll}
\hline & Beta & Significance \\
\hline Demographics & & \\
Gender & $-0.168^{*}$ & n.s. \\
Age & -0.044 & n.s. \\
Completed Educational Level & 0.049 & n.s. \\
$\quad$ Marital status & 0.135 & n.s. \\
$\quad$ Most used language after Arabic & 0.072 & n.s. \\
Familiarity with E learning & $-0.100^{* *}$ & n.s. \\
environment & & \\
Propensity to trust & 0.124 & n.s. \\
Trust intentions & & \\
$\quad$ Willingness to depend & 0.065 & n.s. \\
$\quad$ Subjective probability to depend & $-0.394^{* * *}$ & .000 \\
Offense Severity & 0.346 & .000 \\
\hline$R$ square $=0.28$ Adjusted $R$ square $=0.20$ & &
\end{tabular}

*The negative sign means that they are more likely to be male.

** The negative sign means that they are more likely familiar.

*** Reversed score.
The effect of familarity with E-learning was non-significant on forgiveness (beta $=0.071, \mathrm{P}=0.44$ ). while the effect of offence severity was significant on forgiveness (beta $=0.43, \mathrm{P}<0.001)$. Moreover, proponsity to trust and trusting intentions have significant effects on forgiveness (beta=0.37, $\mathrm{P}<0.05$ and beta $=-0.49, \mathrm{P}<0.05$ respectively). The effect of trust to intention is negative because the forgiveness scale was reversed. In other words, the more the learner intention to trust are high, the less he or she tends to avoid the offender or get even (which means forgiving). For model improvement and based on proposed modification, some covariances between varibales was added in the model. Two pathways between variables display covariances.

\section{DISCUSSION AND CONCLUSION}

This paper began with the premise that trust and forgiveness are critical to learners' adoption of e-learning. Yet, current studies on trust in e-learning may not account for the complex nature of trust and not consider the power of forgiveness. This study proposed and empirically validated a model to predict the effect of learners' propensity to trust and their trusting intentions toward their virtual teams as well as the severity of the offense on learners' forgiveness decision.

The first research questions we aimed to answer in this study was about Algerian learners' trusting intentions toward their virtual teams. Based on the collected responses, most respondents tend to trust their virtual team in the BBA elearning platform. In addition, propensity to trust and trusting intentions were both predictors to forgiveness: the more trusting the learner is, the more forgiving will be. Our study also found that similarly to previous forgiveness studies, the severity of the offense affects negatively the victim decision to forgive. The more severe the offense is, the less the victim will forgive his or her offenders.

The study suggests opportunities for further research. Some of these relate directly to overcoming the limitations of this study. First, the current study relies on an imaginary scenario. Conducting a study based on real offenses and with learners from the e-learning platforms may lead to better and more interesting results. This can allow us to also observe trusting behaviors and social factors (that might affect learners trusting intentions) which were not considered in our model.

Although the present study is helpful for illuminating the role of trust in shaping specific instances of the victim forgiveness, much work remains to be done in illuminating the virtual team characteristics that may also affect forgiveness. In a relative way, it should also be recognized that the present study examined forgiving a single action which is by far the most common approach used in examining forgiving process. 


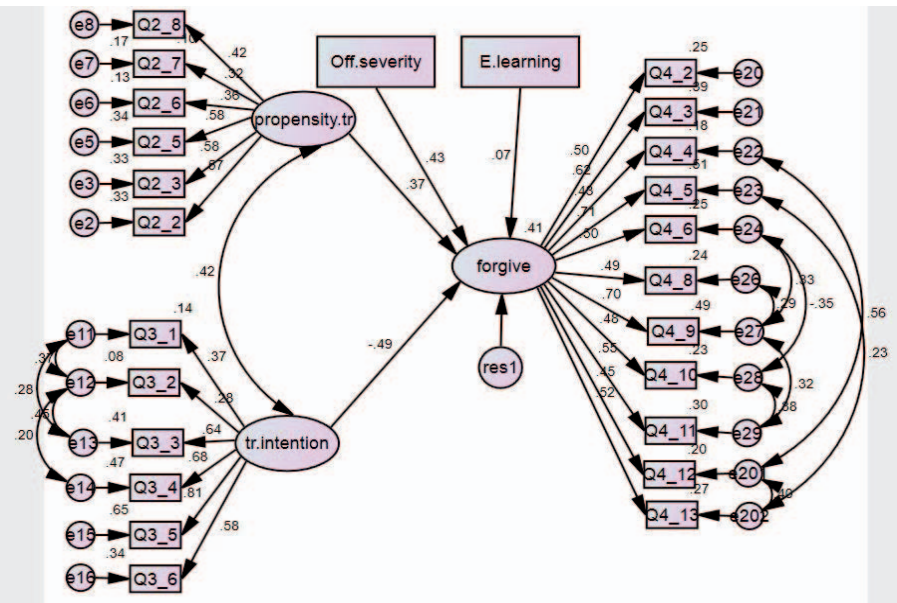

Fig. 2. Result of Model Evaluation

Finally, we believe that adding forgiveness as a component while designing distant learning platforms will enhance learners' performance in general by encouraging more collaboration and giving another chance to virtual teams to fix their mistakes.

\section{REFERENCES}

[1] McKnight, D. H., Choudhury, V., and Kacmar, C. (2002) 'Developing and validating trust measures for e-commerce: An integrative typology', Information Systems Research, Vol. 13 No. 3, pp. 334-359.

[2] R. C. Clark and R.E. Mayer, E-Learning and the science of instruction: Proven Guidelines for Consumers and Designers of Multimedia Learning. $3^{\text {rd }}$ edition. 2011 by John Wiley \& Sons

[3] Rusbult Caryl E., Peggy A. Hannon, Shevaun L. Stocker, Eli J. Finkel. 2005. Forgiveness and Relational Repair. In: Everett L. Worthington, Jr (ed) Handbook of Forgiveness.

[4] Vasalou A., Astrid Hopfensitz, Jeremy V. Pitt (2008): In praise of forgiveness: Ways for repairing trust breakdowns in one-off online interactions. Int. J. Human-Computer Studies 66 (2008) 466 - 480. Elsevier.

[5] Robert E. Slavin: Instruction Based on Cooperative Learning. In R. Mayer (Ed.), Handbook of research on learning and instruction. London: Taylor $\&$ Francis.

[6] McCullough, M. E., Rachal, K. C., Sandage, S. J.,Worthington, E. L., Jr., Brown, S. W., \& Hight, T. L. 1998. Interpersonal forgiving in close relationships. II. Theoretical elaboration and measurement. Journal of Personality and Social Psychology, 75, 1586-1603

[7] Mayer, R. C. and Davis, J. H. (1999) 'The effect of the performance appraisal system on trust for management: A field quasi-experiment', Journal of Applied Psychology, Vol 84 No. 1, pp. 123-136.

[8] B. Shneiderman: Designing trust into online experiences Communications of the ACM, Volume 43 Issue 12, Dec. 2000 Pages 5759.

[9] Pina Tarricone Joe Luca: Successful teamwork: A case study, in Quality Conversations, Proceedings of the 25th HERDSA Annual Conference, Perth, Western Australia, 7-10 July 2002:

[10] Som Naidu, E-learning: A Guidebook of Principles, Procedures and Practices. 2nd Revised Edition, CEMCA, 2006.

[11] Blake M. Riek And Eric W. Mania. 2011. The antecedents and consequences of interpersonal forgiveness: A meta-analytic review. Personal Relationships, 19, 304-325.
[12] Fincham, F., Jackson, H., \& Beach, S. 2005. Transgression severity and forgiveness: Different moderators for objective and subjective severity. Journal of Social and Clinical Psychology, 24, 860-875.

[13] Marsh, S., Briggs, P. 2009. Examining Trust, Forgiveness and Regret as Computational Concepts. In: Golbeck, J. (ed.) Computing with Social Trust. Human-Computer Interaction Series, pp. 9-43. Springer, London.

[14] Donovan Artz, Yolanda Gil. 2007. A survey of trust in computer science and the Semantic Web. Web Semantics: Science, Services and Agents on the World Wide Web journal, Volume 5 Issue 2.

[15] Steven A. Gedeon: How to Measure and Build Intra- and InterOrganizational Trust comments. Submitted 16 January 2013 to the special issue on "The Value of Trust in Entrepreneurship" for the International Journal of Business and Globalisation.

[16] Rosalie Ocker Mary Beth Rosson Dana Kracaw S. Roxanne Hiltz: Training Students to Work Effectively in Partially Distributed Teams. ACM Transactions on Computing Education Volume 9 Issue 1, March 2009 Article No. 6 New York, NY, USA

[17] Ajzen, I., 'Perceived behavioral control, self-efficacy, locus of control, and the theory of planned behavior', Journal of Applied Social Psychology, Vol. 32 No. 4, pp. 665-683. (2006).

\section{Appendix. Measures}

\section{Propensity to Trust}

1. One should be very cautious with strangers.

2. Most experts tell the truth about the limits of their knowledge.

3. Most people can be counted on to do what they say they will do.

4. These days, you must be alert or someone is likely to take advantage of you.

5. Most salespeople are honest in describing their products

6. Most repair people will not overcharge people who are ignorant of their specialty.

7. Most people answer public opinion polls honestly.

8. Most adults are competent at their jobs.

\section{Trusting intentions}

Willingness to depend

1. When an important issue arises about the assignment, I would feel comfortable depending on my virtual team.

2. I can always rely upon my virtual team in a hard assignment.

3. I feel that I could count on my virtual team to help me with a crucial problem about the assignment.

Subjective Probability of Depending

1. If I had a challenging problem about the assignment, I would want to work with my virtual team.

2. I would feel comfortable acting on the information given to me by my virtual team

3. I would feel comfortable giving important information to my virtual team.

\section{Forgiveness}

1. I'll make my virtual team pay. (R)

2. I keep as much distance between me and my virtual team as possible. (A)

3. I wish that something bad would happen to my virtual team. (R)

4. I live as if my virtual team doesn't exist, isn't around. (A)

5. I don't trust my virtual team. (A)

6. I want my virtual team to get what it deserves. (R)

7. I find it difficult to act warmly toward my virtual team. (A)

8. I avoid my virtual team. (A)

9. I'm going to get even. (R)

10. I cut off the relationship with my virtual team. (A)

11. I want to see my virtual team hurt and miserable. (R)

12. I withdraw from my virtual team. (A)

Note. Items on the Avoidance and Revenge subscales are denoted with (A) and (R), respectively. 